\title{
Copper Powder for Termination Electrode in MLCC
}

\author{
Takahiko Sakaue and Katsuhiko Yoshimaru \\ Mitsui Mining \& Smelting Co., Ltd., 1-1-1 Hikoshima-Nishiyama, Shimonoseki, Yamaguchi, 750-0093, Japan
}

Received July 31, 2003

\begin{abstract}
SYNOPSIS
Conventional copper powder used to form terminations of MLCC generally contains large flakes with high aspect ratios and large agglomerate spherical particles. The use of agglomerate powder and large flakes results in low dry film density, and thus a thicker film. In our research, we focused on highly dispersed, uniform, and fine flakes and powder that did not contain coarse particles, and examined the paste characteristics and their effect on firing conditions. We found that a smaller particle size would increase the thixotropic value and result in an earlier start to firing. We also discovered that the agglomerate condition of powder had a significant influence on the rheology of the paste. A higher degree of agglomeration would result in higher viscosity and a higher thixotropic value, but would not have a major effect on the firing condition.
\end{abstract}

KEY WORDS

Copper powder, MLCC, Termination electrode

\section{Introduction}

The paste currently used for the formation of termination of MLCCs is mixed with copper powder, glass frit, and a vehicle. The powder contains agglomerate spherical copper particles with a wide particle-size distribution, large copper flakes, and glass frit with a wide particle-size distribution. Conventional agglomerate powder has low tap density (tap density is an index indicating the propensity for clogging). It is therefore difficult to produce a high-density paste with conventional agglomerate powder, and the powder yields low density with both dry film and fired film ${ }^{12}$. The results of the research indicated that increased powder dispersibility would improve the film density. For highly dispersed micron-size spherical particles, increased dispersibility would adversely affect the density during drying, thus causing swelling and other problems after firing. As the particles were rather large, measuring several microns in diameter, low-temperature firing did not produce acceptable results, and the strength of the fired film was low when fired at the same temperature.

To solve these problems, we conducted research on submicron spherical particles and flakes in an effort to achieve a further reduction in termination thickness. We anticipated that a smaller particle size would lower the firing start temperature and improve the film strength. In the research described in this paper, we used highly dispersible powder with a particle size of $1 \mathrm{~m}$ or less. The small particle size intensifies the effect of powder agglomeration. As we considered powder dispersibility to be the key factor, we closely examined the spherical particles and flakes under various dispersion conditions.

\section{Experimental}

Thermo Mechanical Analysis was measured under 1\% $\mathrm{H} 2-\mathrm{N} 2$ atmosphere, and heating rate was $10^{\circ} \mathrm{C} / \mathrm{min}$. from room temperature to $1000^{\circ} \mathrm{C}$. The oxidation resistance was measured by the thermal gravimetric-differential thermal analysis under air, and heating rate was $10^{\circ} \mathrm{C} / \mathrm{min}$.

In this study, the paste was composed of copper powder with ethyl cellulose-based vehicle. The viscosity was measured from 0.1 to $10 \mathrm{rpm}$. To observed the film appearance, the paste was screen-printed on sintered Alumina substrate, and then the substrate was heated at $400^{\circ} \mathrm{C}$ in 30 minutes, and then was fired at various temperature $\left(600,700,800,900^{\circ} \mathrm{C}\right)$ in one hour in $1 \% \mathrm{H} 2$ N2 atmosphere.

\section{Examination of the Effect of Particle Size}

Using a wet process, we produced spherical copper powder with various particle sizes (ranging from $0.2 \mu \mathrm{m}$ to $1 \mathrm{~m}$ ). Table 1 shows the physical properties of the powder products used in our research, and Fig. 1 shows SEM 
Table 1 Physical properties of copper powder in this study (part 1).

\begin{tabular}{|c|c|c|c|c|}
\hline \multirow{2}{*}{ Type } & Tap density & Surface area & \multicolumn{2}{|c|}{ Particle size $\mu \mathrm{m}$} \\
\cline { 2 - 5 } & $\mathrm{g} / \mathrm{cm} 3$ & $\mathrm{~m} 2 / \mathrm{g}$ & $\mathrm{D} 50$ & $\mathrm{D} 90$ \\
\hline $\mathrm{A}(0.2 \mu \mathrm{m})$ & 3.3 & 2.8 & 0.31 & 0.41 \\
\hline $\mathrm{B}(0.3 \mu \mathrm{m})$ & 3.8 & 2.2 & 0.48 & 0.70 \\
\hline $\mathrm{C}(0.5 \mu \mathrm{m})$ & 4.0 & 1.3 & 0.69 & 0.96 \\
\hline $\mathrm{D}(1.0 \mu \mathrm{m})$ & 4.1 & 0.6 & 1.18 & 1.69 \\
\hline
\end{tabular}

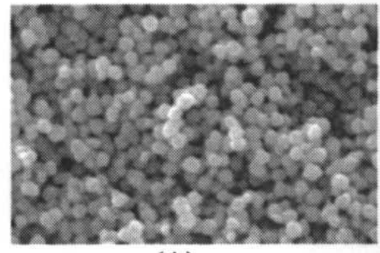

(A)

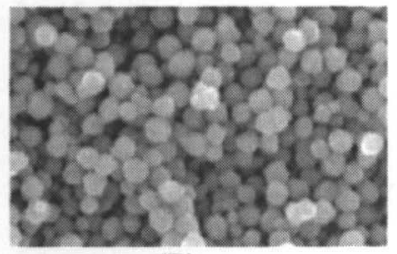

(B)

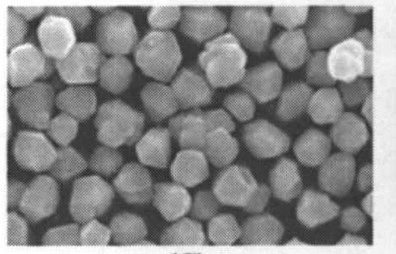

(C)

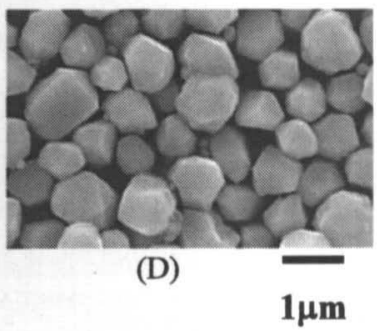

$1 \mu \mathrm{m}$

Fig.1 SEM photographs of various copper powder.

photographs. As indicated in the diagram, the powder had a uniform primary particle diameter and contained no coarse particles. These figures indicate that the powder products used in our research offer higher dispersibility than any other conventional powder products.

We conducted thermal-characteristic evaluation using these powder products. In the TG evaluation, the oxidation start temperature shifted slightly toward the low-temperature side when the particle size was small, but oxidation started at about $150^{\circ} \mathrm{C}$. In the TMA evaluation, smaller particle size lowered the firing start temperature (see Fig. 2).

We also produced paste products using these powder products, and measured their viscosity as the particle size decreased, the viscosity increased sharply at lower shear rates. At high shear rates, however, the viscosity increased only slightly. In other words, the thixotropic value showed a tendency to increase as the particle size decreased.

Fig. 3 shows the results of firing at different temperatures. Similar to the tendency displayed in the TMA evaluation, fusing of powder started earlier with a smaller particle size. In the $0.2-\mu \mathrm{m}$ powder, fusion was in progress before the temperature reached $600^{\circ} \mathrm{C}$. The higher the number of particle contact points in fine powder, the faster firing progressed. We suspect that the increase in the particle size resulted in higher tap density and film density, thus increasing the density of the fired film, which in turn reduced the resistance of the films.

We also examined the degree of agglomeration in $1-\mu \mathrm{m}$ (D) and $0.3-\mu \mathrm{m}$ (B) powder. We applied mechanical dispersion treatment to each powder product. For the $1-\mu \mathrm{m}$

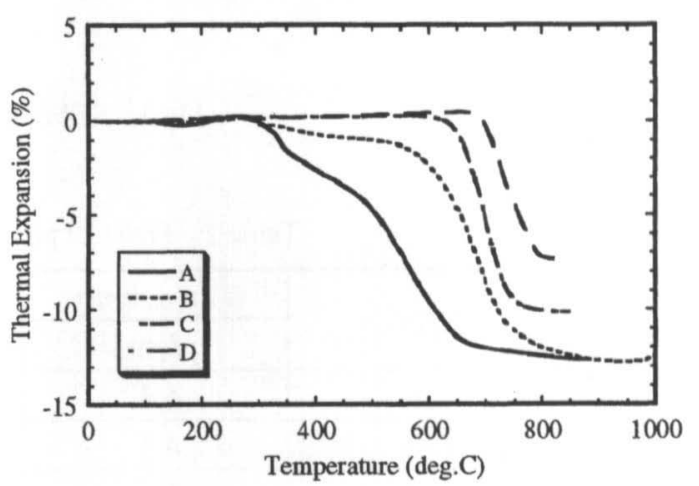

Fig.2 TMA curves of various copper powder.

powder, the dispersion treatment did not cause any noticeable change in the physical properties or rheology of the powder. This suggests that the agglomeration was not strong. In the $0.3 \mathrm{~m}$ powder, the dispersion treatment improved the tap density and caused a sharp drop in the paste viscosity at low shear rates. The finer the powder, the more intense the agglomeration became, but the dispersion treatment was able to lessen the degree of agglomeration. We conducted a firing test using these paste products, and found that the dispersion treatment did not significantly affect the firing condition. Therefore, the research results indicated that the agglomeration of powder would have a larger effect on the paste characteristics than would the firing condition.

\section{Examination of the Effect of Shape}

We produced $1-\mu \mathrm{m}$ powder (D) products with different 
(A)

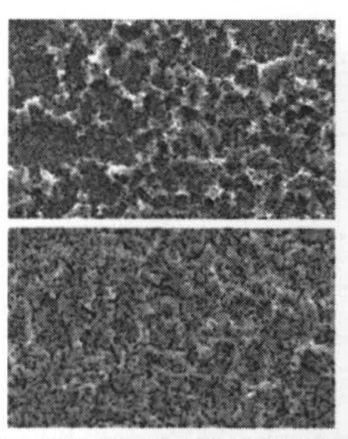

$700^{\circ} \mathrm{C}$

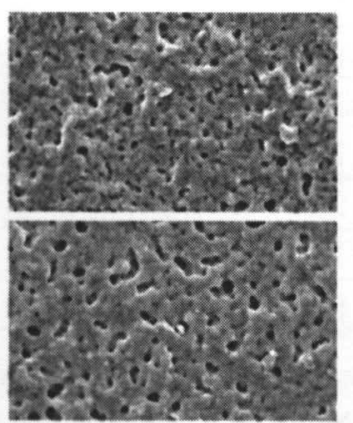

$800^{\circ} \mathrm{C}$

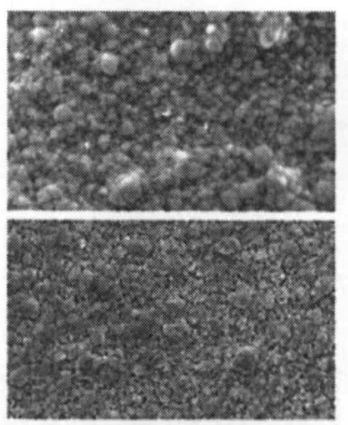

$900^{\circ} \mathrm{C}$
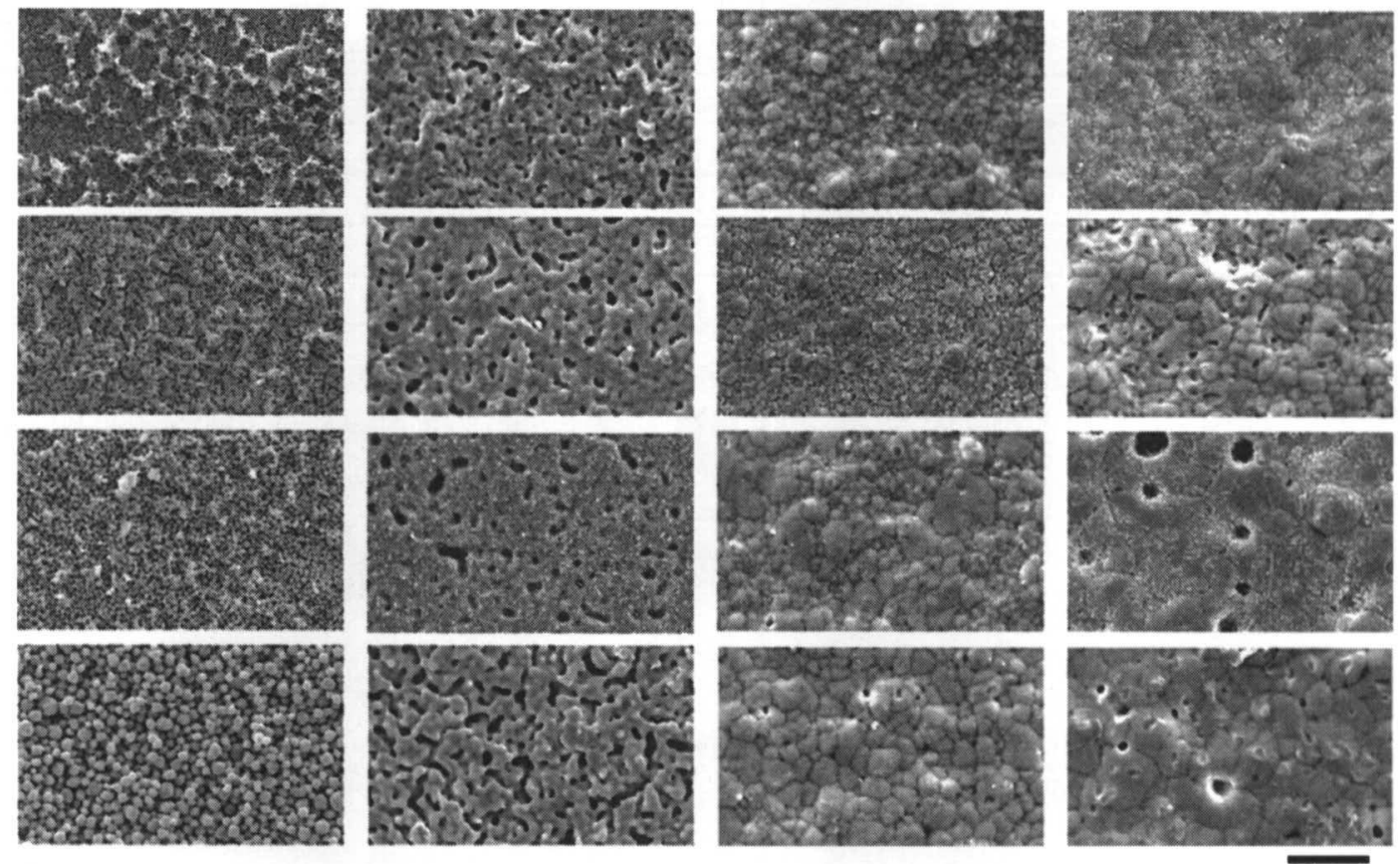

$10 \mu \mathrm{m}$

Fig.3 SEM photographs of the surface of fired film.

Table 2 Physical properties of copper powder in this study (part 3).

\begin{tabular}{|c|c|c|c|c|}
\hline \multirow{2}{*}{ Type } & Tap density & Surface area & \multicolumn{2}{|c|}{ Particle size $\mu \mathrm{m}$} \\
\cline { 2 - 5 } & $\mathrm{g} / \mathrm{cm} 3$ & $\mathrm{~m} 2 / \mathrm{g}$ & $\mathrm{D} 50$ & $\mathrm{D} 90$ \\
\hline $\mathrm{D}$ & 4.1 & 0.6 & 1.18 & 1.69 \\
\hline $\mathrm{D}-1$ & 4.1 & 1.3 & 1.10 & 1.70 \\
\hline $\mathrm{D}-2$ & 3.6 & 1.4 & 1.20 & 1.96 \\
\hline
\end{tabular}

(D)

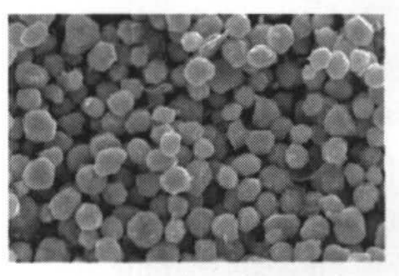

(D-1)

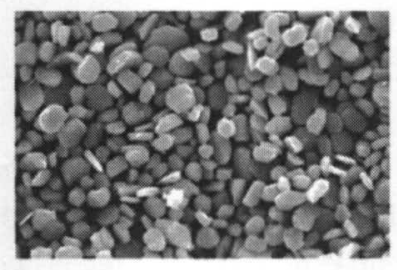

(D-2)

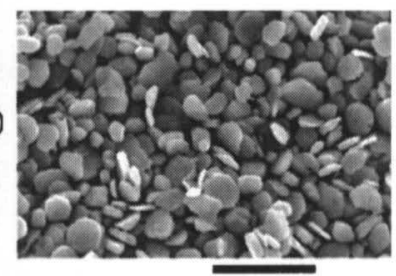

$5 \mu \mathrm{m}$

Fig.4 SEM photographs of various copper powder.

aspect ratios, and conducted evaluation (see Table 2 and Fig.4). The aspect ratio of product D-2 is higher than that of product D-1. As shown in the diagram, the products are highly dispersed uniform flakes without coarse particles. As the aspect ratio increased, the tap density was reduced. However, compared to highly agglomerated powder with wide particle sizes, the tap density is considered high. With regard to the thermal characteristics of these powder products, the TMA evaluation showed no major change in the shrinkage start temperature. However, a higher aspect ratio resulted in a higher shrinkage rate. We suspect that a rise in the aspect ratio lowered the filling density. The evaluation of the paste products made based on evaluation of the above-mentioned powder revealed that a higher aspect ratio would result in a higher viscosity at low shear rates, as well as a higher thixotropic value. Compared to 
conventional flakes, the powder products used in our research were higher in dispersibility, which would allow the viscosity to be reduced in order to create paste with density as high as PWC $85 \mathrm{wt} \%$, to achieve improved film density. This paste resulted in the uniform firing of all particles, as shown in Fig. 5. Because the increased aspect ratio reduced the number of particle contact points in powder and lowered the tap density, more holes tended to remain uniform. The resistance of the fired film also increased slightly as the aspect ratio was raised, but it was still low, at a level of $4 \times 10 \mathrm{e}-6 \Omega$-cm or below. We believe that this is attributable to the uniformity in firing conditions.

In order to obtain suitable rheology and firing characteristics, a mixture of spherical particles and flakes is normally used at present. However, our research results indicated that control of the particle size, agglomeration, and aspect ratio would enable the required firing characteristics to be achieved using only one type of powder.

\section{Summary}

With regard to spherical particles, the degree of agglomeration has a major effect on the rheology of paste. Powder with a low degree of agglomeration enables the production of high-density paste for the formation of low-

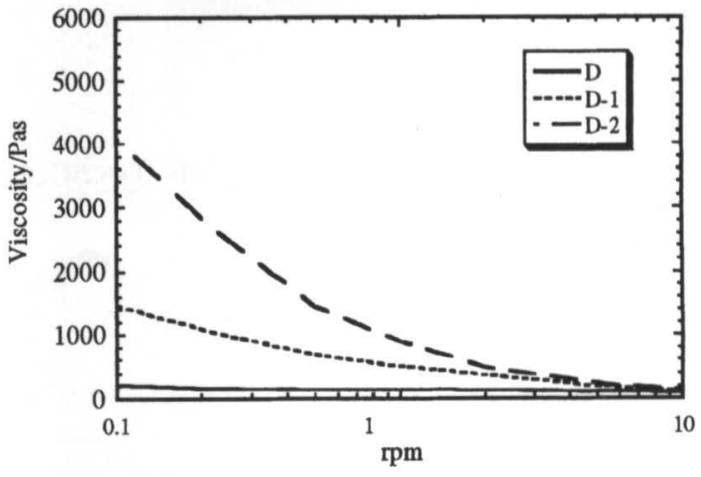

Fig.5 Viscosity at various shear rate with various copper powder.

resistance fired film. As the particle size decreases, the thixotropic value of the paste increases. As for flakes, the flake size has a significant effect on the paste characteristics (viscosity, thixotropic value). We believe that control of the particle and flake sizes allows flexible application to various firing profiles.

\section{Reference}

1) T.Sakaue, Y.Uwazumi, T.Sasaki and T.Hayashi: Proceedings CARTS 2001.
(D-1)

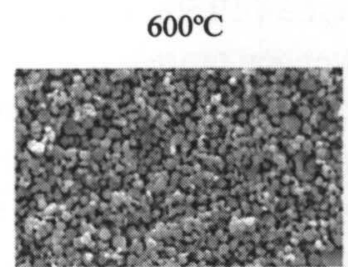

(D-2)

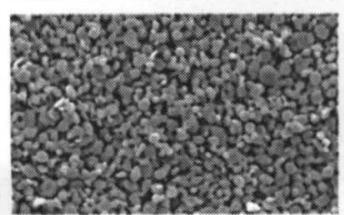

$700^{\circ} \mathrm{C}$
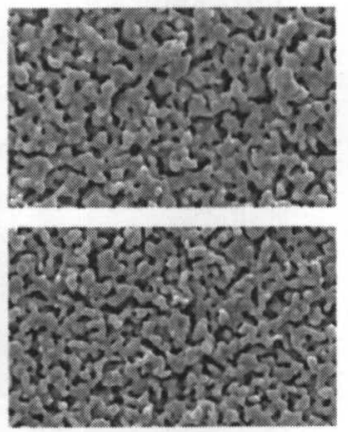

$800^{\circ} \mathrm{C}$
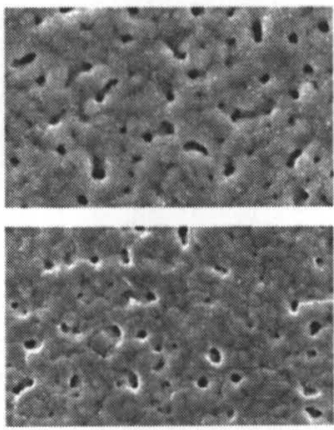

$900^{\circ} \mathrm{C}$
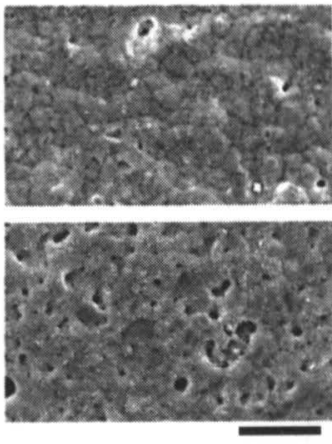

$10 \mu \mathrm{m}$

Fig.6 SEM photographs of the surface of fired film. 